\title{
Люминесцентные свойства высокоомного кремния, облученного тяжелыми ионами высоких энергий
}

\author{
(C) С.Г. Черкова ${ }^{1}$, В.А. Скуратов ${ }^{2,3,4}$, В.А. Володин ${ }^{1,5}$ \\ ${ }^{1}$ Институт ффизики полупроводников им. А.В. Ржанова Сибирского отделения Российской академии наук, \\ 630090 Новосибирск, Россия \\ ${ }^{2}$ Объединенный институт ядерных исследований, \\ 141980 Дубна, Россия \\ ${ }^{3}$ Национальный исследовательский ядерный университет „МИФИ“, \\ 115409 Москва, Россия \\ ${ }^{4}$ Государственный университет Дубна, \\ 141982 Дубна, Россия \\ ${ }^{5}$ Новосибирский государственный университет, \\ 630090 Новосибирск, Россия \\ E-mail: cherkova@isp.nsc.ru
}

Поступила в Редакцию 16 апреля 2019 г.

В окончательной редакции 15 мая 2019 г.

Принята к публикации 17 июня 2019 г.

Исследованы оптические свойства высокоомного кремния, облученного тяжелыми ионами высоких энергий. В спектрах фотолюминесценции при низких температурах, помимо известных линий от $\mathrm{X}, \mathrm{W}, \mathrm{W}^{\prime}$, $\mathrm{R}$ и $\mathrm{C}$ линий, проявляется широкий пик в области 1.3-1.5 мкм. При этом с увеличением дозы облучения в диапазоне $3 \cdot 10^{11}-10^{13} \mathrm{~cm}^{-2}$ наблюдается спад и сужение пика ФЛ с одновременным смещением максимума в длинноволновую область.

Ключевые слова: фотолюминесценция, дефекты в кремнии, быстрые тяжелые ионы.

DOI: 10.21883/FTP.2019.11.48441.9142

\section{1. Введение}

Проблема создания на основе кремния источника света, интегрированного в электронные микросхемы, остается актуальной. К настоящему времени разработаны волноводы, коммутаторы и приемники света, изготавливаемые с использованием планарной кремниевой технологии [1]. Наиболее значимой задачей сегодня является создание излучателей на длине волны $\sim 1.5$ мкм, что соответствует окну прозрачности волоконной оптики. Поскольку кремний является непрямозонным материалом, вероятность излучательной рекомбинации возбужденных носителей заряда невелика. Существует несколько основных подходов к решению этой проблемы. Одним из них является использование внутрицентровой люминесценции ионов эрбия $\mathrm{Er}^{3+}$ в кристаллическом, аморфном или нанокристаллическом кремнии на длине волны 1.54 мкм ( 0.805 эВ) [2,3]. Другим важным подходом является формирование наноструктур $\mathrm{SiGe} / \mathrm{Si}$ [4]. Кроме того, большого внимания заслуживает дислокационная люминесценция в кремнии [5-11]. Хорошо известно, что дислокации в кристаллическом $\mathrm{Si}$ создают глубокие энергетические уровни в запрещенной зоне. Так, в пионерской работе [8] было показано, что при изгибных деформациях в пластины $\mathrm{Si}$ вводятся дислокации, дающие при $T \sim 4 \mathrm{~K}$ набор узких линий люминесценции в диапазоне энергий $0.812-1.000$ эВ. Природа светоизлучающих центров обсуждается до сих пор. Проблемой также остается подавление каналов безызлучательной рекомбинации. В работе [10] была получена электролюминесценция при комнатной температуре с внешним кпд более $0.1 \%$ на дислокациях скольжения в кремнии, подверженном одноосному сжатию при 750-770 ${ }^{\circ} \mathrm{C}$. Высокая эффективность достигалась за счет геттерирования и пассивации центров безызлучательной рекомбинации. Пики фотолюминесценции (ФЛ) в области $0.8-1.0$ эВ наблюдались также после отжигов кристаллического $\mathrm{Si}$, подвергнутого облучению электронами и ионами средних энергий [11-15]. Возникновение узких пиков ФЛ связывалось с введением дефектов, вакансионных кластеров.

В нашей работе исследованы люминесцентные свойства высокоомного кремния при облучении тяжелыми ионами высоких энергий. Облучение высокоэнергетическими ионами широко применяется для модификации свойств материалов. Для такого типа ионов характерны высокие потери на ионизацию в приповерхностных областях, они достигают десятков кэВ/нм. При облучении кристаллических $\mathrm{Si}$ и $\mathrm{Ge}$ тяжелыми ионами в них не наблюдались треки и протяженные дефекты независимо от уровня электронного торможения [16,17]. Отметим, что люминесцентные свойства кристаллического кремния, облученного высокоэнергетичными ионами, практически не исследованы, есть лишь несколько работ на эту тему. $\mathrm{B}$ работе [18] при облучении кремния ионами $\mathrm{Ni} \mathrm{c}$ энергией $80 \mathrm{MэB,} \mathrm{флюенсами} 1 \cdot 10^{11}-5 \cdot 10^{13} \mathrm{~cm}^{-2}$ с последующим анодным травлением, на образцах пористого 
кремния наблюдали ФЛ в видимой области 600-750 нм. С ростом дозы облучения происходил сдвиг максимума ФЛ в длинноволновую область. В работе [19] при облучении $n-\mathrm{Si}$ (удельное сопротивление $0.56-12.5 \mathrm{OM} \cdot \mathrm{M}$ ) ионами ${ }^{36} \mathrm{Ar}$ с энергией $6.7 \mathrm{MэВ/нуклон} \mathrm{до} \mathrm{дозы}$ $10^{14} \mathrm{~cm}^{-2}$ авторы наблюдали интенсивный узкий пик ФЛ при температуре $10 \mathrm{~K}(1.018$ эВ), который связывали с появлением вакансионных кластеров, эту линию ФЛ называют $\mathrm{W}$-полосой $[14,15,20]$. Недавно созданы криогенные кремниевые светодиоды, излучающие на этой линии [20]. Таким образом, люминесцентные свойства кремния, облученного тяжелыми ионами высоких энергий, представляют интерес.

\section{2. Описание эксперимента}

Для облучения мы использовали пластины высокоомного кремния (удельное сопротивление составляло 2000 Ом · см), выращенные методом безтигельной зонной плавки, с ориентацией (111). Для того чтобы исключить влияние эффектов загрязнения поверхности в процессе имплантации ионов, пластины были покрыты защитным пассивирующим термическим окислом кремния толщиной 35 нм. Далее, подложки высокоомного монокристаллического кремния облучали при комнатной температуре ионами ${ }^{132} \mathrm{Xe}^{26+}$ с энергией $167 \mathrm{MэB}$ в диапазоне флюенсов от $3 \cdot 10^{11}$ до $10^{13} \mathrm{~cm}^{-2}$ на циклотроне ИЦ-100 ЛЯР ОИЯИ (г.Дубна). Согласно расчетам по программе SRIM (www.srim.org), пробег ионов Хе составлял 19.9 мкм. Потери на ионизацию в приповерхностном слое достигали 12.5 кэВ/нм. Оптические свойства пленок контролировались с помощью метода спектроскопии фотолюминесценции. Возбуждение на длинах волн 325 и 488 нм проводилось с помощью газового Не-Cd-лазера и твердотельного диодного лазера соответственно. Для исследования температурной зависимости ФЛ использовался гелиевый криостат с точностью установки температуры $\pm 0.5 \mathrm{~K}$. Спектры ФЛ измеряли с использованием монохроматора, снабженного решеткой 600 линий/мм и охлаждаемого жидким азотом InGaAs-диодом в качестве детектора. Длинноволновый край порога чувствительности составлял 1650 нм.

\section{3. Результаты и обсуждение}

На рис. 1 представлены низкотемпературные спектры ФЛ при возбуждении 325 нм образцов кремния после облучения высокоэнергетичными ионами Хе в диапазоне флюенсов $3 \cdot 10^{11}-10^{13} \mathrm{~cm}^{-2}$. Для сравнения приведен спектр необлученного образца (кривая 1), в котором наблюдаются пики ФЛ от электронно-дырочных переходов с участием фононов. В облученных образцах эти пики пропадают, но в области $1150-1600$ нм $(1.1-0.77$ эВ наблюдается широкая полоса ФЛ. Помимо этого, виден набор узких пиков, которые можно соотнести с

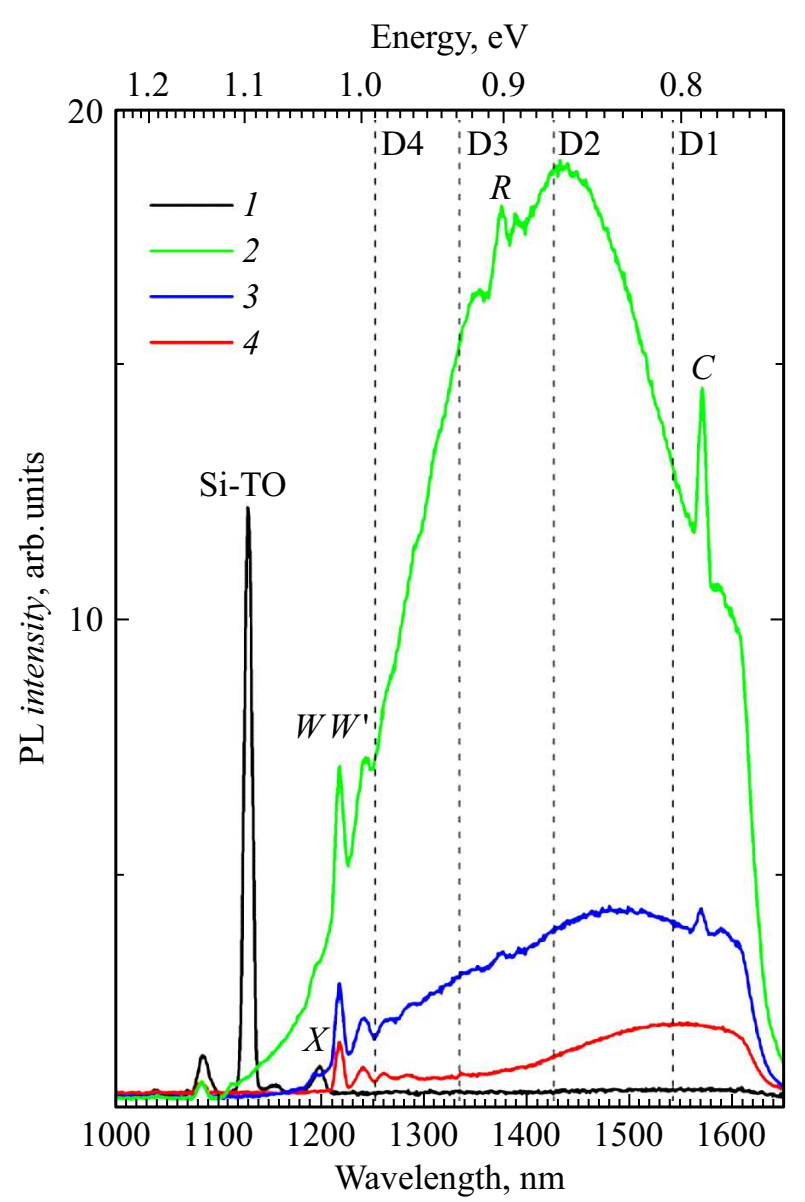

Рис. 1. Спектры ФЛ $\left(10 \mathrm{~K}, \lambda_{\mathrm{ex}}=325 \mathrm{Hм}\right)$ слоев $\mathrm{Si}$, облученных ионами Хе, дозами, $\mathrm{cm}^{-2}: 1-0,2-3 \cdot 10^{11}, 3-2 \cdot 10^{12}$, $4-10^{13}$.

известными в литературе: X (1.033 эВ), W (1.018 эВ), $\mathrm{W}^{\prime}(1.0048$ эB) и связываемыми с мелкими межузельными кластерами, R (0.901 эВ) ассоциируемый с $\{311\}$ дефектами и $\mathrm{C}(0.79$ эВ $)$ - обычно приписываемым комплексам C-O $[12-15,21,22]$. На рис. 1 видно, что при увеличении дозы облучения от $3 \cdot 10^{11}$ до $10^{13} \mathrm{~cm}^{-2}$ максимум ФЛ смещается в длинноволновую область, а интенсивность сигнала падает примерно на порядок. Обратим внимание на то, что положение наблюдаемой широкой полосы примерно совпадает с положением известных ,дислокационных“ пиков D1 ( 0.81 эВ), $\mathrm{D} 2(\sim 0.87$ эВ), D3 ( 0.93 эВ) и $\mathrm{D} 4(\sim 0.99$ эВ) (рис. 1, вертикальные пунктирные прямые) $[6,8,11]$. Однако в случае дислокационно-индуцированной ФЛ эти 4 пика относительно узкие и разрешаются в спектре. В нашем случае, хотя и в широкой полосе наблюдаются некоторые особенности, разложение на пики с максимумами, соответствующими известным линиям D1-4, не приводит к хорошей аппроксимации экспериментального спектра. Однако все же в качестве одной из гипотез можно предположить, что наблюдаемый нами широкий пик ФЛ обусловлен дефектами дислокационного типа. Мало вероятно, что это достаточно протяженные дислокации 
сдвига [16], возникающие при введении в пластины кремния пластических деформаций, а скорее это плотные сетки локально ограниченных вблизи треков ионов дислокационных дефектов. Такие дефекты могут быть следствием релаксации импульсных термоупругих механических напряжений, возникающих вокруг траектории иона, как результат локального импульсного разогрева. Интересно, что в литературе относительно широкие пики дислокационной люминесценции появляются в спектрах после дополнительных отжигов выше $400^{\circ} \mathrm{C}[6,14]$. Широкая полоса ФЛ (схожая с наблюдаемой нами) регистрировалась непосредственно после облучения (без отжигов) ионами $\mathrm{B}^{+}$с энергией 150 кэВ [12]. Авторы [12] не обсуждали природу возникновения этой полосы.

Наблюдаемое падение сигнала ФЛ с ростом дозы облучения можно объяснить введением при облучении центров безызлучательной рекомбинации (типа оборванной связи) и конкуренцией этих центров с излучающими дефектными комплексами. С ростом дозы облучения становится возможным перекрытие треков частиц.

На рис. 2 представлена температурная зависимость спектров ФЛ при возбуждении 325 нм слоев $\mathrm{Si}$, облученных ионами Хе дозой $3 \cdot 10^{11} \mathrm{~cm}^{-2}$. С ростом температуры наблюдается гашение ФЛ. Отметим, что при этом изменяется форма спектров ФЛ. Интенсивность коротковолнового вклада в спектр ФЛ сильнее спадает с ростом температуры, длинноволновая часть ФЛ более стабильна. При температуре $150 \mathrm{~K}$ сигнал ФЛ становится сравним с шумом и практически не наблюдается. Температурное гашение интенсивности ФЛ можно объяснить ростом вероятности безызлучательной рекомбинации. С ростом температуры растет вероят-

\section{Energy, eV}



Рис. 2. Температурная зависимость спектров ФЛ $\left(\lambda_{\mathrm{ex}}=325 \mathrm{Hм}\right)$ слоев $\mathrm{Si}$, облученных ионами Хе дозой $3 \cdot 10^{11} \mathrm{~cm}^{-2}$.

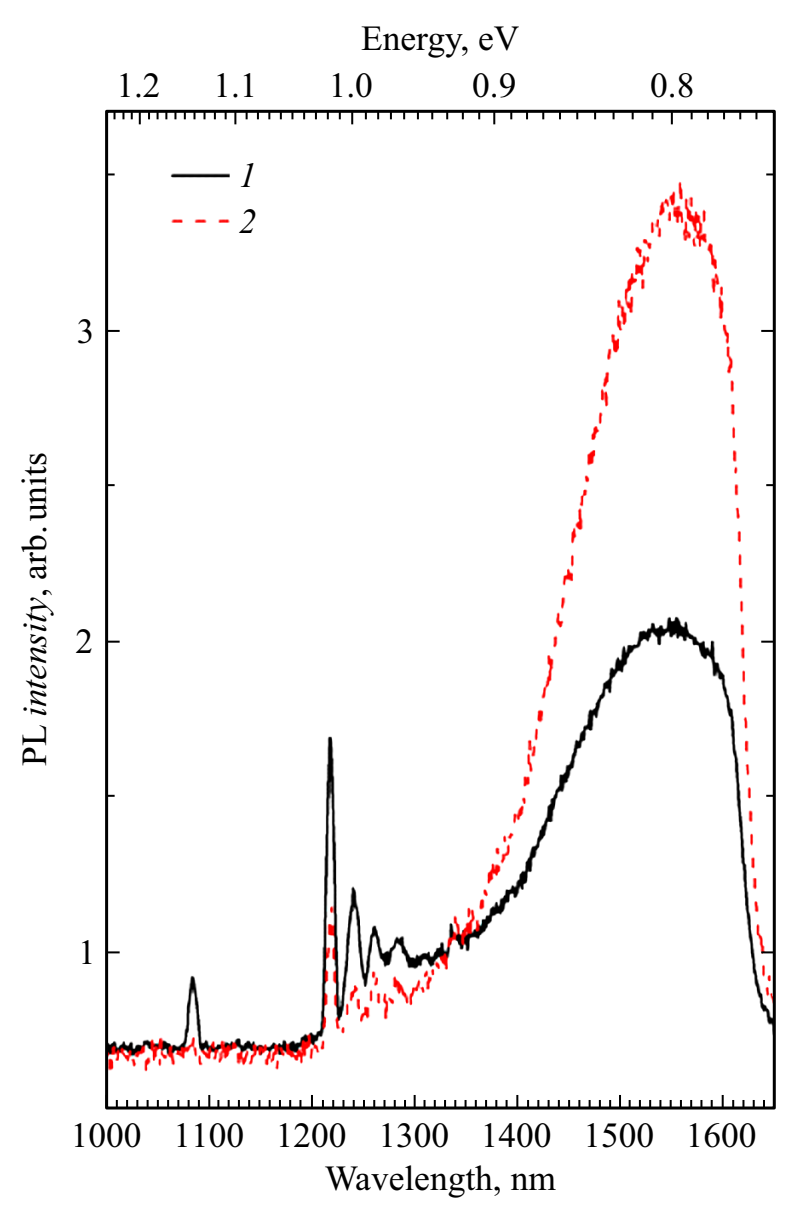

Рис. 3. Спектры ФЛ слоев $\mathrm{Si}$, облученных ионами Хе дозой $10^{13} \mathrm{~cm}^{-2}$ при возбуждении $\lambda_{\mathrm{ex}}=325 \mathrm{Hм}(1)$ и $\lambda_{\mathrm{ex}}=488 \mathrm{Hм}(2)$.

ность миграции возбужденных электронов и дырок к центрам безызлучательной рекомбинации [23].

На рис. 3 показаны спектры ФЛ для образца с максимальной дозой облучения при возбуждении источниками с различными энергиями фотонов. При увеличении длины волны возбуждения с 325 до $488 \mathrm{Hм}$ мы наблюдали увеличение интенсивности ИК полосы ФЛ с максимумом $\sim 0.8$ эВ в 1.5 раза. Позиция пика не изменялась. При этом интенсивность узких пиков с положением между 1200 и 1300 нм при возбуждении фотонами с длиной волны 488 нм (2.54 эВ) падает в сравнении со случаем, когда для возбуждения использовалось ультрафиолетовое излучение (325 нм, 3.82 эВ). Отметим, что в первом случае (сине-зеленые фотоны) глубина проникновения фотонов в кремний составляет 500 нм, а во втором (УФ фотоны) она составляет 10 нм. Таким образом, можно предположить, что узкие пики (вышеупомянутые центры $\mathrm{X}, \mathrm{W}$ и $\mathrm{W}^{\prime}$ ) формируются в основном в приповерхностной области кремния. Широкая полоса ФЛ, скорее всего, обусловлена вкладом плотной сетки локально ограниченных вблизи треков ионов дислокационных дефектов, которая возникает вдоль всей длины треков. 


\section{4. Заключение}

При облучении кремния тяжелыми ионами высоких энергий в ИК-области появляется широкая ФЛ с максимумом 1.3-1.5 мкм. При этом с ростом дозы от $3 \cdot 10^{11}$ до $10^{13} \mathrm{~cm}^{-2}$ происходит уменьшение интенсивности ФЛ. Предполагается, что при облучении вдоль траектории частиц формируются сетки дислокаций за счет вводимых дефектов и нагрева, вызванного сильной ионизацией. Наблюдаемый широкий пик ФЛ, предположительно, обусловлен рекомбинацией на этих дефектах.

\section{Благодарности}

Работа выполнена по государственному заданию Программа фундаментальных исследований ИФП СО РАН № 0306-2019-0019. Авторы благодарны профессорам М. Stoffel и М. Vergnat (Université de Lorraine, Institut Jean Lamour, Франция) за помощь в измерении спектров ФЛ.

\section{Конфликт интересов}

Авторы заявляют об отсутствии конфликта интересов.

\section{Список литературы}

[1] C. Sun, M.T. Wade, Y. Lee, J.S. Orcutt, L. Alloatti, M.S. Georgas, A.S. Waterman, J.M. Shainline, R.R. Avizienis, S. Lin, B.R. Moss, R. Kumar, F. Pavanello, A.H. Atabaki, H.M. Cook, A.J. Ou, J.C. Leu, Y.H. Chen, K. Asanović, R.J. Ram, M.A. Popović, V.M. Stojanović. Nature, 528, 534 (2015).

[2] H. Ennen, G. Pomrenke, A. Axmann, K. Eisele, W. Haidl, J. Schneider. Appl. Phys. Lett., 46, 361 (1985).

[3] В.Ю. Тимошенко, О.А. Шалыгина, М.Г. Лисаченко, Д.М. Жигунов, C.A. Тетеруков, П.К. Кашкаров, D. Kovalev, M. Zacharias, K. Imakita, M. Fujii. ФTT, 47, 116 (2005).

[4] H. Sunamura, N. Usami, Y. Shiraki, S. Fukatsu. Appl. Phys. Lett., 66, 3024 (1995).

[5] А.А. Шкляев, А.В. Латышев, М. Ичикава. ФТП, 44, 452 (2010).

[6] Н.А. Соболев. ФТП, 44, 3 (2010).

[7] Н.А. Соболев, А.Е. Колядин, В.И. Сахаров, И.Т. Серенков, Е.Н. Шек, Е.О. Паршин, Н.С. Мелесов, С.Г. Симакин. ФТП, 53, 165 (2019).

[8] Н.А. Дроздов, А.А. Патрин, В.Д. Ткачев. Письма ЖЭТФ, 23, 651 (1976).

[9] V.V. Kveder, E.A. Steinman, S.A. Shevchenko, H.G. Grimmeiss. Phys. Rev. B, 51, 10520 (1995).

[10] V.V. Kveder, M. Badylevich, E.A. Steinman, A. Izotov, M. Seibt, W. Schröter. Appl. Phys. Lett., 84, 2106 (2004).

[11] L.I. Fedina, A.K. Gutakovskii, T.S. Shamirzaev. J. Appl. Phys., 124, 053106 (2018).

[12] C.G. Kirkpatrick, J.R. Noonan, B.G. Streetman. Rad. Eff., 30, 97 (1976).

[13] C.E. Jones, E.S. Johnson, W.D. Compton, J.R. Noonan, B.G. Streetman. J. Appl. Phys., 44, 5402 (1973).

[14] V.D. Tkachev, C. Schrödel, A.V. Mudryi. Rad. Eff., 49, 1333 (1980).
[15] Y. Yang, J. Bao, C. Wang, M.J. Aziz. J. Appl. Phys., 107, 123109 (2010).

[16] F. Studer, M. Hervieu, J.-M. Constantini, M. Toulemonde. Nucl. Instrum. Meth. B, 122, 449 (1997).

[17] Ф.Ф. Комаров. УФН, 173, 1287 (2003).

[18] V.S. Vendamani, S.V.S. Nageswara Rao, A.P. Pathak. Nucl. Instrum. Meth. B, 315, 188 (2013).

[19] P. Mangiagalli, M. Levalois, P. Marie, P.G. Rancoita, M. Rattagi. Nucl. Phys. B (Proc. Suppl.), 61B, 464 (1998).

[20] S. Buckley, J. Chiles, A.N. McCaughan, G. Moody, K.L. Silverman, M.J. Stevents, R.P. Mirin, S.W. Nam, J.M. Shainline. Appl. Phys. Lett., 111, 141101 (2017).

[21] S. Coffa, S. Libertino, C. Spinella. Appl. Phys. Lett., 76, 321 (2000).

[22] P.K. Giri. Semicond. Sci. Technol., 20, 638 (2005).

[23] V.A. Volodin, V.A. Stuchinsky, S.G. Cherkova, G.A. Kachurin, R.A. Yankov. ECS Transactions, 16, 105 (2009).

Редактор Г.А. Оганесян

\section{Luminescent properties of float zone silicon irradiated with swift heavy ions}

\section{S.G. Cherkova ${ }^{1}$, V.A. Skuratov ${ }^{2,3,4}$, V.A. Volodin ${ }^{1,5}$}

${ }^{1}$ Rzhanov Institute of Semiconductor Physics,

Russian Academy of Sciences,

630090 Novosibirsk, Russia

2 Joint Institute for Nuclear Research,

141980 Dubna, Russia

${ }^{3}$ National Research Nuclear University „MEPhl“,

115409 Moscow, Russia

${ }^{4}$ Dubna State University,

141982 Dubna, Russia

${ }^{5}$ Novosibirsk State University, 630090 Novosibirsk, Russia

Abstract The float zone (high-resistance) silicon irradiated with swift heavy ions was studied by photoluminescence (PL) spectroscopy method. In addition to well-known $\mathrm{X}, \mathrm{W}, \mathrm{W}^{\prime}, \mathrm{R}$ and $\mathrm{C}$ lines, a broad peak $(1.3-1.5 \mu \mathrm{m})$ appears in PL spectra at low-temperatures. As the irradiation dose increases from $3 \cdot 10^{11}$ to $10^{13} \mathrm{~cm}^{-2}$, the PL intensity decreases by about an order of magnitude, also a narrowing of the peak with red-shift is observed. 